\title{
Does Beta Explain Global Equity Market Volatility - Some Empirical Evidence
}

\author{
Radosław Kurach ${ }^{1}$
}

ABSTRACT

The purpose of this study is to assess the diversification benefits resulting from international asset allocation. In this study, we examine Capital Asset Pricing Model (CAPM) in its international context (ICAPM) using the monthly equity returns for 26 countries (18 developed and 8 emerging markets) between July 1996 and June 2011 and adopting the US investor's perspective. We verify the beta-return trade-off employing two approaches: the unconditional trade-off and the conditional relationship. In this latter case, we find the country beta to be a significant variable explaining the cross-country variation of returns. Next, we test the degree of market integration in the light of the ICAPM. The results of this test indicate that country-idiosyncratic risks are generally not priced. In the subsidiary outcomes of our verification procedure, we argue that country betas are timevarying and that currently, global factors are the dominant source of equity market volatility. Consequently, the opinion regarding emerging market assets and their role in global portfolio management should be reconsidered. The results of the entire study may provide essential implications for fund managers because the decreasing international diversification gains have been identified.

KEY WORDS: $\quad$ international CAPM; country betas; time-varying betas; equity markets integration; diversification gains

JEL Classification: G11, G12, G15

'Wrocław University of Economics, Poland

\section{Introduction}

The position of the CAPM in finance is unique for several reasons.

CAPM is a mandatory topic in every academic course on financial markets. The general conclusion of CAPM implies that the expected return for any security is positively related to the risk carried by this asset. This relationship is represented by the following equation:

$$
\left.E\left(R_{i}\right)=R_{f}+\beta_{i}\left[E\left(R_{m}\right)-R_{f}\right)\right]
$$

Correspondence concerning this article should be addressed to: Radosław Kurach, Wrocław University of Economics, Faculty of Economic Sciences, ul. Komandorska 118/120, 53-345 Wrocław, Poland, e-mail: radoslaw.kurach@ue.wroc.pl where $E\left(R_{i}\right)$ is the expected return on asset $i, R_{f}$ is a risk-free return, $E\left(R_{m}\right)$ is the expected return on the market portfolio, and the expression $\left.\left[E\left(R_{m}\right)-R_{f}\right)\right]$ is known as the market risk premium. The trade-off between risk and return was recognized in finance before Sharpe (1964), Lintner (1965) and Mossin (1966) developed the concept of CAPM. The key contribution of this model, therefore, lies in the employed measure of risk represented by $\beta_{i}=\operatorname{cov}\left(R_{i}, R_{m}\right) / \operatorname{var}\left(R_{m}\right)$. The theory distinguishes two types of risk: idiosyncratic and systematic. The first type of risk is connected with events that are specific to a company and that affect the returns of a single security. Events such as introducing a new product, hiring a well-respected manger or damage to a factory are examples. The second type of risk represents the risk that is common for all compa- 
nies and that leads to broader market volatility. It is crucially important to understand that idiosyncratic risk can be eliminated by holding a diversified portfolio. Hence, in the CAPM world, the expected return on any security is related only to the portion of the total risk that is generated by the common risk factor. Rational and risk-averse investors should a hold diversified portfolio with no idiosyncratic risk, so the unsystematic component should not be priced.

CAPM is also one of the most debatable financial models because of its rigid assumptions and diverse empirical record. Well-known early CAPM empirical verifications are Douglas (1969), Black, Jensen and Scholes (1972) and, finally, the seminal work by Fama and MacBeth (1973).

Contrary to the CAPM assumptions, Douglas (1969) found the idiosyncratic component to be a significant factor that affected the expected returns. Black Jensen and Scholes (1972) decided to utilize monthly data on the combined portfolios' returns rather than on the individual equities. In their approach, one obtains more precise beta estimates because most of the firm-specific risk is diversified while holding the asset portfolio. It is also worth underlining that monthly data are less noisy, which supports the stability of the estimates. In Black et al's study, the positive and linear relationship between beta and the expected return was confirmed. Fama and MacBeth (1973) also rejected the significance of a squared beta and idiosyncratic volatility while confirming the linear relationship between beta and the average return.

Since the beginning of the eighties, the extensive research devoted to other factors affecting average returns has been conducted. Banz (1981) described the phenomenon that is currently recognized as the "size effect". He found that the market value of equity capital better describes the cross-sectional average return volatility than beta. Higher returns were observed in smallcapitalization companies rather than in large-cap stocks. Later, Fama and French (1992) suggested extending the CAPM to a three-factor model, adding market capitalization and book-to-market value variables.

The empirical results have not been unanimous, and even the possibility of testing CAPM is not clear. Roll (1977) questioned whether CAPM can be verified because the market portfolio should contain all types of investment assets, making it unobservable. Finally,
Pettengill, Sundaram and Mathur (1995) argued that many studies fail to capture the beta-return relationship because of the improper use of realized returns to test a relationship described in terms of expected returns. The problem of using realized returns for CAPM verification was previously known; However, the standard defense was to argue that rational investors are, on average, right; thus, a long time series should properly reflect expectations (Elton, Gruber, Brown \& Goetzman, 1995, p. 339). Pettengill et al. (1995) state that this argument is not enough. When the realized returns are employed in an up market in which the risk premium is positive, the relationship between beta and the asset return should also be positive. However, if the realized market return falls below the risk-free rate, the high-beta assets should experience larger downward swings than the low-beta assets. In any other case, no risk-averse investor would be willing to hold low-beta assets. The CAPM equation assumes that there is a positive risk premium, which is true in the long run. An empirical verification, however, needs higher frequency data, in which the market return may be sometimes negative. This requirement is why Pettengill et al. (1995) argue that in empirical tests, the beta-return relationship should have a conditional form. After implementing this idea, they found beta to be a significant factor in explaining the realized returns for US stocks.

Many of the existing CAPM empirical studies have been conducted in a local context focusing on the US market. As the era of financial deregulation and free capital flows began in the seventies, and a decade later the process of political and economic transition began in Latin America and then in Central and Eastern Europe, the importance of adding a dimension to reflect international investing increased. Literature devoted to the international CAPM (ICAPM) has emerged, and the results of these considerations may have vital meaning. In the case of ICAPM, the systematic risk is related to global fluctuations, while the idiosyncratic factor represents country-specific factors such as political stability or the general governance level. If ICAPM holds, the country-specific risk is not priced.

In fact, the verification of the validity of ICAPM or another asset pricing model provides an opportunity to answer questions about the stock market integration process. Jappelli and Pagano (2008) argue that the law of one price holds in an integrated financial market. 

Secondly, we separately estimate for every country the degree of equity market integration to verify whether the country idiosyncratic risk is priced by the investors. We find little evidence in favor of market segmentation, which brings us to the conclusion that the common understanding of an "emerging stock market" may be a little bit outdated.

Last but not least, along the way, we document the time-varying behavior of the country betas and formulate some recommendations for future research.

The paper is organized as follows. In section 2, we discuss the methodology employed in this study, while section 3 contains the data description. The empirical results are presented in section 4, leaving section 5 for the concluding comments and suggestions for further research.

\section{Methodology}

Many empirical studies that verify CAPM validity use the general three-step research framework as proposed by Fama and MacBeth (1973). First, the equity betas are estimated, and the relative ranking of companies respective to the estimated betas is created. The equities are then split into $n$ portfolios, of which the first portfolio consists of the lowest beta equities, the next lowest beta firms are placed in the second portfolio, while the last $n$-th portfolio groups the riskiest stocks in terms of market risk. The portfolios are created to diversify the firms' idiosyncratic risk and to obtain more reliable estimates of the portfolios' betas. In the international context, we can skip this stage, using data on country portfolios, not single equities, as an input. Hence, we start from the second step, in which the portfolio (country indices) betas $\beta_{c}$ are OLS estimated against the market (World Index) returns from the following regression:

$\left(R_{c t}-R_{f t}\right)=\beta_{c}\left(R_{W t}-R_{f t}\right)+\varepsilon_{c t}$

where $R_{c t}$ is the return on country index $c$ in period $t$, $R_{f t}$ is the worldwide risk-free rate in period $t, R_{W t}$ is the return on the world market portfolio proxy in period $t$, and $\varepsilon_{c t}$ represents the random error term, normally i.i.d. Following Fama and MacBeth (1973), in the last step of the procedure, the obtained estimates of $\beta_{c}$ are used in the cross-section (cross-country) regressions estimated by OLS separately for each period $t$ :

$R_{c t}=\hat{\gamma}_{0 t}+\hat{\gamma}_{1 t} \beta_{c}+\mu_{c t}$ where $\mu_{c t}$ is the random error term. The estimates $\hat{\gamma}_{1 t}$ are then averaged across periods to verify whether they are statistically higher than zero. Fama and MacBeth (1973) suggest employing the following $t$ statistics:

$t\left(\overline{\hat{\gamma}}_{j}\right)=\frac{\overline{\hat{\gamma}}_{j} \sqrt{T}}{s\left(\hat{\gamma}_{j}\right)}$,

where $\overline{\hat{\gamma}}_{j}$ is the period-by-period average of the regression coefficient estimates, $s\left(\hat{\gamma}_{j}\right)$ is the analogically standard deviation, and $T$ is the number of analyzed periods.

Pettengill et al. (1995) argue that this last step needs reconsideration because the realized, not the expected, returns are used. The assumption of a positive risk-return trade-off requires the market return to be higher than the risk-free rate. As we mentioned before, when using realized returns, the return on the market portfolio frequently falls below the risk-free rate. No matter whether the risk-return trade-off holds in terms of expected returns, investors must be aware that there exists a nonzero probability of a negative risk premium in terms of the realized returns. In such a case, lowbeta assets should generate lower losses than high-beta securities. If this conclusion is not accurate, no riskaverse investor would be eager to keep low-beta assets because they would be always inferior to the high-beta assets. This concern is why Pettengill et al. (1995) test the following conditional beta-return relationship instead of the unconditional form (_unconditional 3):

$R_{c t}=\hat{\gamma}_{0 t}+\hat{\gamma}_{2 t} \delta \beta_{c}+\hat{\gamma}_{3 t}(1-\delta) \beta_{c}+\mu_{c t}$

where $\delta$ is a dummy variable that equals one if the market risk premium is positive and zero otherwise Hence, $\gamma_{2}$ is the market risk premium when the market return exceeds the risk-free rate (up market), while $\gamma_{3}$ defines the market risk premium when the market return falls below the risk-free rate (down market). The hypotheses to be tested are then the following:

$H_{0}: \overline{\hat{\gamma}}_{2}=0$

$H_{a}: \overline{\hat{\gamma}}_{2}>0$ '

$H_{0}: \overline{\hat{\gamma}}_{3}=0$

$H_{a}: \overline{\hat{\gamma}}_{3}<0$

Similarly to Fama and MacBeth (1973), the above hypotheses should be verified using a $t$ test (_tstat 4).

Pettengill et al. (1995) state that the conditional relationship (_conditional 5) is not a sufficient condi- 
tion for a positive risk-return trade-off, To guarantee a situation in which an investor is positively rewarded for holding riskier assets, the average market risk premium should be positive, and the market risk premium in up and down markets should be symmetrical. The condition regarding the average risk premium is verified using $t$ tests (_tstat 4 ), while the symmetry of premiums is tested by the following hypotheses:

$H_{0}: \overline{\hat{\gamma}}_{2}-\overline{\hat{\gamma}}_{3}=0$,

$H_{a}: \overline{\hat{\gamma}}_{2}-\overline{\hat{\gamma}}_{3} \neq 0$

which employ the standard two population $t$-test. One should remember to reverse the sign of $\hat{\gamma}_{3 t}$ and reestimate the mean value.

To test the degree of local market integration with the rest of the world, the law of one price is applied. Markets are perfectly integrated when the assets carrying the same level of risk are priced the same across countries. If ICAPM is the appropriate asset valuation model, only the world market risk should be priced. To verify the hypothesis of perfect integration, Korajczyk (1995) and Levine and Zervos (1998) suggest estimating the following equation separately for every country:

$\left(R_{c t}-R_{f t}\right)=\alpha_{c}+\beta_{c}\left(R_{W t}-R_{f t}\right)+\varepsilon_{c t}$

Under perfect integration, the assessment of the pricing error intercept $\alpha_{c}$ should be equal to zero for every country. Conversely, if the estimate of $\alpha_{c}$ is significantly different from zero, it indicates the existence of country-idiosyncratic factors affecting the asset valuation in country $c$; hence, the market segmentation is identified.

\section{Data description}

This empirical study covers the monthly log returns between July 1997 and June 2011 for 26 counties: 18 developed and 8 emerging markets. The availability of a long time series was the main determinant for the chosen sample. The country stock returns $\left(R_{c t}\right)$ are approximated by the MSCI country equity US dollar indices, while the MSCI World Equity USD Index is used to represent the world market portfolio $\left(R_{W t}\right)$ variable. Therefore, because we employ the USD denominated indices, our results will reflect the perspective of the US investor. We decided to employ the 3-month US Treasury Bill rate as a proxy for the global risk-free rate
$\left(R_{f t}\right)$. The yearly T-bill rates are converted to monthly frequency, assuming continuous compounding. All of the time series used in this study have been obtained from Reuters Datastream.

The basic descriptive statistics for the equity indices along with the beta OLS estimates are presented in Table 1.

A quick analysis of the data presented in Table 1 reveals two basic stylized facts.

In the long run, all of the emerging markets offer a higher average return and are more risky in terms of the standard deviation than the world market portfolio proxy. The emerging markets usually also carry a higher level of global market risk, and we can find the highest values for the country betas in the emerging market subsample (Turkey, Russia, and Hungary).

Another interesting conclusion arises after a careful study of the $R^{2}$ parameters for the estimated regressions. In our case, the interpretation of this statistic is straightforward and very meaningful. A higher determinant coefficient indicates less country idiosyncratic risk and lower diversification gains from international investing. Hence, one may find emerging markets quite attractive for global asset allocation.

The results presented in Table 1 should, however, be treated with caution. Being aware of the conclusions from empirical studies that report that the country beta may be time-varying, we applied the Chow stability test to the obtained estimates. As a rule of thumb, we decided to establish the breakpoint in the middle of our sample. The results rejected the hypothesis of no break in thirteen cases (Austria, Belgium, Czech Republic, Denmark, Hungary, India, Ireland, Norway, Poland, South Africa, Switzerland, the UK, and the USA) at the $1 \%$ significance level, four cases (Brazil, France, Greece, and the Netherlands) at the 5\% significance level, two cases (Germany and Portugal) at the $10 \%$ significance level, while in only seven cases (Finland, Italy, Japan, Russia, Spain, Sweden, and Turkey), the null could not be rejected. Therefore, the separate estimation of the betas for the two subperiods is justified.

After splitting the initial sample period into halves, the estimation results (Table 2) exhibit two other interesting phenomena. First of all, consistent with the results of the Chow test, the beta coefficients for many countries are highly time-varying. Secondly, the determination coefficients increased for all of the investigat- 
Table 1. Summary statistics: July 1996 - June 2011

\begin{tabular}{|c|c|c|c|c|}
\hline Country & Mean & $\sigma$ & $\beta$ & $\mathrm{R}^{2}$ \\
\hline Austria & 0.464 & 8.113 & 1.089 & 0.546 \\
\hline Belgium & 0.240 & 7.643 & 1.118 & 0.651 \\
\hline Denmark & 0.796 & 7.192 & 1.076 & 0.675 \\
\hline Finland & 0.591 & 9.903 & 1.366 & 0.579 \\
\hline France & 0.456 & 6.927 & 1.155 & 0.846 \\
\hline Germany & 0.407 & 7.277 & 1.190 & 0.813 \\
\hline Greece & -0.066 & 10.475 & 1.126 & 0.352 \\
\hline Ireland & 0.040 & 8.027 & 1.172 & 0.650 \\
\hline Italy & 0.286 & 7.643 & 1.162 & 0.705 \\
\hline Japan & -0.207 & 6.030 & 0.701 & 0.404 \\
\hline Netherlands & 0.301 & 7.220 & 1.209 & 0.855 \\
\hline Norway & 0.591 & 9.276 & 1.338 & 0.631 \\
\hline Portugal & 0.253 & 7.057 & 0.908 & 0.504 \\
\hline Spain & 0.585 & 7.587 & 1.132 & 0.675 \\
\hline Sweden & 0.651 & 8.605 & 1.384 & 0.783 \\
\hline Switzerland & 0.550 & 5.753 & 0.920 & 0.775 \\
\hline UK & 0.302 & 6.113 & 1.020 & 0.848 \\
\hline USA & 0.407 & 5.593 & 0.977 & 0.927 \\
\hline Brazil & 0.880 & 11.950 & 1.500 & 0.476 \\
\hline Czech Rep. & 0.880 & 9.153 & 1.025 & 0.376 \\
\hline Hungary & 0.870 & 12.219 & 1.562 & 0.494 \\
\hline India & 0.732 & 10.016 & 1.087 & 0.355 \\
\hline Poland & 0.429 & 10.758 & 1.363 & 0.487 \\
\hline Russia & 1.232 & 16.347 & 1.665 & 0.312 \\
\hline South Africa & 0.532 & 9.022 & 1.102 & 0.451 \\
\hline Turkey & 0.722 & 15.793 & 1.760 & 0.376 \\
\hline World & 0.314 & 5.513 & - & - \\
\hline
\end{tabular}

Note: The table presents summary statistics calculated for the monthly dollar returns for the MSCl equity indices of 26 countries: 18 developed (placed at the upper part of the table) and 8 emerging economies (placed below). The final row of the table reports the statistics for the MSCI World Dollar Equity Index. The sample period covers 15 years (180 months) between July 1996 and June 2011. The monthly mean returns and standard deviations are reported in percentage points. All beta parameters that are OLS estimated with respect to the MSCI World Dollar Equity Index are significant at the 1\% level. The last column presents the coefficients of determination for the estimated regressions (4). 

Table 3. Unconditional beta-return relationship

\begin{tabular}{lccc}
\hline & July 1997 - June 2011 & July $1997-$ Dec. 2003 & Jan. 2004 - June 2011 \\
\hline$\overline{\hat{\gamma}}_{1}$ & $0.006301(0.9102)$ & $0.006038(0.5511)$ & $0.006564(0.7698)$ \\
\hline
\end{tabular}

Note: The table reports the OLS mean estimates $\left(\overline{\hat{\gamma}}_{1}\right)$ of the market risk premium from equation (3). The one-tail t statistics (4) are in parentheses. For every sample period, the separate set of beta estimates obtained for this period is used.

$*^{* *}$ and ${ }^{* * *}$ : the coefficient is significant at the $10 \%, 5 \%$ and $1 \%$ levels, respectively.

Table 4. Conditional beta-return relationship

\begin{tabular}{|c|c|c|c|}
\hline & July 1997 - June 2011 & July 1997 - Dec. 2003 & Jan. 2004 - June 2011 \\
\hline N & 102 & 46 & 56 \\
\hline$\overline{\hat{\gamma}}_{2}$ & $0.0467(6.9678)^{* * *}$ & $0.0605(5.1708)^{* * *}$ & $0.0353(4.8589)^{* * *}$ \\
\hline N & 78 & 44 & 34 \\
\hline$\overline{\hat{\gamma}}_{3}$ & $-0.0465(-4.3077)^{* * *}$ & $-0.0509(-3.5057)^{* * *}$ & $-0.0407(-2.4993)^{* * *}$ \\
\hline$\overline{\hat{\gamma}}_{2}-\overline{\hat{\gamma}}_{3}=0$ & 0.015306 & 0.517018 & 0.346610 \\
\hline$R_{W}-R_{f}$ & $0.001335(0.3248)$ & $0.001318(0.3409)$ & $0.001352(0.3099)$ \\
\hline
\end{tabular}

Note: The table reports the OLS mean estimates $\left(\overline{\hat{\gamma}}_{2}\right.$ and $\overline{\hat{\gamma}}_{3}$ ) of the market risk premiums from equation (5) in up and down market months, respectively. The one-tail t statistics (4) are in parentheses. For every sample period, the separate set of beta estimates obtained for this period is used. $\mathrm{N}$ in the upper row is the number of up-market months, whereas $\mathrm{N}$ in the lower row indicates the number of down-market months. The results of the $t$ test as to whether $\overline{\hat{\gamma}}_{2}-\overline{\hat{\gamma}}_{3}=0$ are presented in the bottom part of the table. The last row reports the world market risk premium and the one-tail t test (in parentheses) indicates whether this premium is significantly higher than zero.

$*^{* *}$ and ${ }^{* * *}$ : the coefficient is significant at the $10 \%, 5 \%$ and $1 \%$ levels, respectively.

ed markets. This observation confirms that the local equity market fluctuations are becoming more global and responding less to country-idiosyncratic shocks.

\section{Empirical results}

The relationship between beta and the returns is examined both in unconditional (_unconditional 3) and conditional form (_conditional 5). We estimate these equations for the entire sample period and separately for the two subperiods. Tables 3 and 4 present the summarized results:

As we can see, the flat (unconditional) relationship does not hold for the entire sample period or for any of the examined subperiods. The estimates of the $\gamma_{1}$ coefficient are not statistically significant. This result is no longer surprising when we take a quick look at the number of down market months reported in Table 4 , which in every case is a large share of the overall number of months. The significant and positive $\gamma_{1}$ would indicate that high-beta markets perform better independent of the global conditions. However, this case is not ours.

The estimates reported in Table 4 exhibit the opposite story. The conditional relationship is valid any time at a $1 \%$ significance level, which is a strong support for beta as a global investing risk measure. Compared to a low-beta country, a higher beta describes a market that gains more during a global bull market but also suffers more under bearish global conditions. Therefore, beta may identify the aggressive and defensive markets for 
Table 5. Time-varying betas proof

Jan. 2004 - June 2011

\begin{tabular}{lc}
\hline$\overline{\hat{\gamma}}_{1}$ & $0.0031(0.2852)$ \\
$\mathrm{N}$ & 56 \\
$\overline{\hat{\gamma}}_{2}$ & $0.0011(0.0892)$ \\
$\mathrm{N}$ & 34 \\
$\overline{\hat{\gamma}}_{3}$ & $0.006381(-0.3115)$ \\
\hline
\end{tabular}

Note: The table reports the OLS mean estimates $\left(\overline{\hat{\gamma}}_{1}, \overline{\hat{\gamma}}_{2}\right.$ and $\overline{\hat{\gamma}}_{3}$ ) of the market risk premiums from equations (3) and (5), respectively. The monthly returns from the January 2004 - June 2011 sample are regressed by the beta estimates for July 1997 - December 2003. The one-tail t statistics (4) are in parentheses. N in the upper row is the number of up-market months, whereas $\mathrm{N}$ in the lower row indicates the number of down-market months.

$*^{*}, * *$ and ${ }^{* * *}$ : the coefficient is significant at the $10 \%, 5 \%$ and $1 \%$ levels, respectively.

international asset allocation. A similar argument was presented by Fletcher (2000); therefore we need to distinguish the contribution of our study. Fletcher (2000), verifying the conditional beta-return relationship, analyzed the period from January 1970 to July 1998 for 18 developed markets. His results were not as evident as ours because he observed in one of the examined subperiods a lack of statistical significance at the $5 \%$ level for $\gamma_{2}$. As we updated the sample period, our results became more robust despite our adding 8 emerging markets, which are still perceived by many investors as being less correlated with global fluctuations. Actually, these results can be easily explained if we examine the estimates of $R^{2}$ presented in Table 2. An increase of the coefficient values indicates that global shocks explain over half of the variation of the local returns. In this case, beta must be a meaningful measure of risk.

We also did not reject the null hypothesis on premiums symmetry (_hypotheses2 7), which is favorable for the conditional CAPM. On the contrary, the estimations of the global risk premium are the only controversial estimates. For the entire sample and for both of the subperiods, the premiums are positive, but statistically insignificant. The annualized values are, respectively $1.61 \%$. $1.59 \%$. and $1.63 \%$. However, we do not consider these results to be crucial for verifying the validity of the CAPM after analyzing the standard deviation of the world portfolio returns. Compared to the results obtained by Fletcher (2000), who analyzed data ending in July 1998, in our case, the standard deviation for the MSCI world monthly returns is over one percentage point higher. In the last fifteen years, we witnessed events that were manifested in large market swings, i.e., the Asian crisis (1997-98), the Russian default (1998), the dotcom bubble bursting (2000) and, finally, the unprecedented global financial crisis that started in approximately 2007 . The higher volatility of the world returns explain why the global risk premium estimates are not statistically significant.

Lastly, in this part, we decided to focus on the timevarying behavior of beta. We estimated equations (_unconditional 3) and (_conditional 5) for the entire sample period using betas from Table 1, being aware that in many cases the Chow test rejected the hypothesis of coefficient stability. Using estimates that are, to some extent, inappropriate, we still received highly statistically significant results in the conditional beta relationship case. However, global managers may face the following challenge: how reliable are the past beta estimates when the investment decisions are oriented toward the future? If investors are rational, they should be, on average, right, and the "true" beta for the investment period should be uncovered. This assumption is very strong. However, contrary to CAPM predictions, the investors may form their expectations in a naive way by extrapolating from the past. We decided to verify equations (_unconditional 3) and (_conditional 5) by regressing the returns from the second subperiod using the betas estimated in the first subperiod. 
Table 6. Pricing errors

\begin{tabular}{cc}
\hline & \multicolumn{1}{c}{$\alpha_{c}$} \\
\hline Brazil & $0.0120(1.7409)^{*}$ \\
Czech Rep. & $0.0114(1.7562)^{*}$ \\
Ireland & $-0.0107(-2.0924)^{* *}$ \\
\hline
\end{tabular}

Note: The table reports the significant OLS estimates of pricing errors $\alpha_{c}$ from equation (8). The sample period starts January 2004 and ends June 2011.

$*^{* *}$ and ${ }^{* * *}$ : the coefficient is significant at the $10 \%, 5 \%$ and $1 \%$ levels, respectively.

The results (Table 5) of this example are evident and confirm the time-varying behavior of country betas because the lack of statistical significance applies both to the conditional and the unconditional relationships. Betas estimated on the past data cannot explain cross-country variation in the long investment horizon. Hence, an investor that does not at least temporarily update these estimates eliminates an important investment indicator.

The second research target focused on the potential country-risk premiums required by the investors. Again, we estimated equation (_integration 8) for the entire sample period as well as for both of the subperiods. Out of 78 regressions ( 26 countries times 3 estimation periods), we found significant pricing errors in only three cases and only for the second estimation subperiod (Table 6).

Therefore, the investigated equity markets appear to be highly integrated.

\section{Conclusions}

Our research confirms the positive beta-return tradeoff and integration of local equity markets. These results may have serious practical implications. At the same time, these results pose a few new questions requiring further in-depth research.

We note the cross-country as well as the time-series variation of beta. It is tempting to verify the possible determinants leading to the observed differences. In one of the early studies regarding the time-variation of equity betas, Fabozzi and Francis (1978) estimate the betas of US securities using a random coefficient model. They also list the possible explanations for the systematic risk time-dependence phenomenon. First, microeconomic factors such as changes in the dividend payouts or leverage may influence beta over time.
Second, macroeconomic conditions, namely business cycle fluctuations and inflation variability, are noted. The third group consists of political factors, e.g., labor legislation, pollution-control legislation and elections. Last, but not least, the financial market conditions (bull and bear markets, credit crunches) may also be important for beta determination. The importance of macroeconomic factors is further verified by Andersen, Bollerslev, Diebold, and Wu (2005), while Liodakis, Brar, Crenian and Dowle (2003) focus their attention on the micro fundamentals of the analyzed companies. The research on country beta variation has primarily investigated this phenomenon in a time series context. Wdowinski (2004) estimate the model of Poland's beta with real and monetary factors and find the monetary factors to be relatively more powerful in explaining the country's systematic risk. However, the cross-country variation of betas, in our opinion, deserve more attention. These differences cannot be explained by only macroeconomic factors, which are becoming more global as we noted before. Rather, we suggest analyzing the importance of market liquidity and depth. Global capital flows on less-deep markets may result in higher volatility reflected in higher beta estimates.

The problem of proper country beta estimation when the time-variation of country systematic risk is identified is still debatable. Again, there exists a group of studies supportive of the Kalman-filter technique, but most of these studies are conducted using single stocks or industry portfolios (Bulla \& Mergner 2008; Faff, Hillier \& Hillier, 2000; He \& Kryzanowski 2008).

We have delivered very few arguments against equity market integration. This finding should be compared with the beta estimation results for the second subperi- 
od (Table 2), which reveal that over half of the local variance is explained by the global market portfolio fluctuations, even in the case of emerging markets. There are several reasons for an increase in financial market interdependence, and these reasons can be classified into two broad groups: fundamental and non-fundamental reasons. The fundamental group of linkages describes channels of spreading market impulses via changes in the foreign trade volume or responses to global shocks such as an oil price increase. The non-fundamental interconnections may be the result of financial intermediaries operating globally (Valdés, 1997), or they may have their roots in information asymmetries and coordination problems (Dornbusch, Park \& Claessens, 2001). Forbes and Rigobon (2002) argue that these latter interconnections can only, but not always, be observed during time of crisis, thereby constituting a phenomenon recognized as contagion. Rising global interconnections lead us to formulate the final conclusion that the potential diversification gains from international investing have been substantially reduced over recent years. Some empirical studies even found that cross-industry diversification was more effective than the cross-country pattern in terms of portfolio risk reduction (Baca, Garbe, \& Weiss, 2000; Brooks and Del Negro 2002; Baele et al., 2004). Currently, emerging markets differ from developed ones mainly in terms of their beta risk. Global investors should, therefore, use emerging markets assets to adjust their portfolio beta rather than diversifying country-idiosyncratic risk.

Finally, one should keep in mind that the presented results reflect the US investor's perspective. It would be quite interesting to discover if the same conclusions hold when the returns are denominated in different currencies, especially if we adopt the emerging markets perspective. We hope to develop this issue in further research.

\section{References}

Agénor, P.-R. (2003). Benefits and Costs of International Financial Integration: Theory and Facts. The World Economy, 26(8), 1089-1118.

Andersen, T. G., Bollerslev, T., Diebold, F. X., \& Wu, J. (2005). A framework for exploring the macroeconomic determinants of systematic risk (Working Paper No. 11134). Retrieved from NBER website: http://www.nber.org/papers/w11134.pdf
Baca, S. P., Garbe, B., \& Weiss, R. A. (2000). The Rise of Sector Effects in Major Equity Markets. Financial Analysts Journal, 56(5), 35-40.

Baele, L., Ferrando, A., Hördahl, P., Krylova, E. Monnet, C. (2004). Measuring financial integration in the euro area (Occasional Paper Series No. 14). European Central Bank.

Banz, R. W. (1981). The relationship between return and market value of common stock. Journal of Financial Economics, 9(1), 3-18.

Black, F., Jensen M. C. \& Scholes, M. (1972). The Capital Asset Pricing Model: Some Empirical Tests. In M. C. Jensen (Ed.), Studies in the Theory of Capital Markets (pp. 79-121) New York, NY: Praeger Publishers.

Brooks, R., \& Del Negro, M. (2002). Firm-Level Evidence on Globalization. IMF and Federal Reserve Bank of Atlanta. Mimeo. Retrieved from http:// www.eu-financial-system.org/fileadmin/content/Dokumente_Events/launching_workshop/ Brooks.pdf

Bulla, J., \& Mergner, S. (2008). Time-varying Beta Risk of Pan-European Industry Portfolios: A Comparison of Alternative Modeling Techniques. The European Journal of Finance, 14(8), 771-802.

Douglas, G. (1969). Risk in the Equity Markets: An Empirical Appraisal of Market Efficiency. Yale Economic Essays, 9(1), 3-45.

Dornbusch, R., Park, Y. C., \& Claessens, S. (2001). Contagion. Why Crises Spread and How This Can Be Stopped. In S. Claessens, \& K. Forbes (Eds.), International Financial Contagion (pp. 1942). New York, NY: Kluwer Academic Publishers.

Elton, E. J., Gruber, M. J., Brown, S. J., \& Goetzman, W. N. (1995). Modern Portfolio Theory and Investment Analysis ( $5^{\text {th }}$ ed.). Hoboken, NJ: John Wiley \& Sons.

Fabozzi, T. J., \& Francis, J. C. (1978). Beta as a Random Coefficient. The Journal of Financial and Quantitative Analysis, 13(1), 101-116.

Faff, R.W., Hillier, D., \& Hillier, J. (2000). Time Varying Beta Risk: An Analysis of Alternative Modelling Techniques. Journal of Business Finance \& Accounting, 27(5-6), 523-554.

Fama, E. F., \& French, K. R. (1992). The Cross-Section of Expected Stock Returns. The Journal of Finance, 47(2), 427-465. 
Fama, E. F., \& MacBeth, J. D. (1973). Risk, Return, and Equilibrium, Empirical Tests. Journal of Political Economy, 81(3), 608-636.

Fidrmuc, J., \& Korhonen, I. (2006). Meta-Analysis of the Business Cycle Correlation between the Euro Area and the CEECs (Working Paper No. 1693). CESifo Group Munich.

Fletcher, J. (2000). On the conditional relationship between beta and return in international stock returns. International Review of Financial Analysis, 9(3), 235-245.

Forbes, K. J., \& Rigobon, R. (2002). No Contagion, Only Interdependence, Measuring Stock Market Comovements. The Journal of Finance, 57(5), 2223-2261

Puls Biznesu (2005, August 8) Foreign investors increase their presence. Puls Biznesu online. Retrieved from http://www.pb.pl/1404437,69566,foreigninvestors-increase-their-presence

Harvey, C. R., \& Zhou, G. (1993). International asset pricing with alternative distributional specifications. Journal of Empirical Finance, 1(1), 107-131.

He, Z. L., \& Kryzanowski, L., (2008). Dynamic betas for Canadian sector portfolios. International Review of Financial Analysis, 17(5), 1110-1122.

Jappelli, T., \& Pagano, M. (2008). Financial Market Integration under EMU (European Economy Economic Papers No. 312). Directorate General Economic and Monetary Affairs (DG ECFIN), European Commission.

Korajczyk, R. A. (1995), A measure of stock market integration for developed and emerging markets (Policy Research Working Paper Series No. 1482) The World Bank

Korajczyk, R. A., \& Viallet, C. A. (1989). An Empirical Investigation of International Asset Pricing. Review of Financial Studies, 2(4), 553-585.

Kose, M. A., Otrok, C., \& Whiteman, C. H. (2003). International Business Cycles, World, Region, and Country-Specific Factors. American Economic Review, 93(4), 1216-1239.

Levine, R. \& Zervos, S. (1998). Stock Markets, Banks, and Economic Growth. American Economic Review, 88(3), 537-558.

Liodakis, M., Brar, G., Crenian, R., \& Dowle, M. (2003). Estimating Betas Using Fundamentals - A New Approach to Compute Stock Betas. Technical report, Citigroup Smith Barney, Equity Research Europe, Quantitative Strategy.

Lintner, J. (1965). The valuation of risk assets and the selection of risky investments in stock portfolios and capital budgets. The Review of Economics and Statistics, 47(1), 13-37.

Mossin, J. (1966). Equilibrium in a Capital Asset Market. Econometrica, 34(4), 768-783.

MSCI Emerging Markets Index. (n.d.). Retrieved June 01, 2013 from the MSCI Investopedia http://www. investopedia.com/terms/e/emergingmarketsindex.asp\#axzz2021nYmeA

Pettengill, G. N., Sundaram, S., \& Mathur, I. (1995). The Conditional Relation between Beta and Returns, The Journal of Financial and Quantitative Analysis 30(1), 101-116.

Roll, R. (1977). A critique of the asset pricing theory's tests Part I: On past and potential testability of the theory. Journal of Financial Economics, 4(2), $129-176$

Sharpe, W. F. (1964). Capital asset prices, A theory of market equilibrium under conditions of risk. The Journal of Finance, 19(3), 425-442.

Shyh-Wei, C., \& Nai-Chuan, H. 2007. Estimates of the ICAPM with regime-switching betas, evidence from four pacific rim economies. Applied Financial Economics, 17(4), 313-327.

Valdés, R. (1997). Emerging Market Contagion, Evidence and Theory (Working Papers No. 7). Central Bank of Chile.

Wdowiński, P. (2004). Determinants of Country Beta Risk in Poland (Working Paper No. 1120). CESifo Group Munich.

\section{Acknowledgments}

The author thanks two anonymous referees for their valuable comments. 